\title{
Hoffa Fracture Treated using a Lateral Femoral Epicondylar Osteotomy: Case Report
}

Juan Manuel Concha*, Humberto González, Julián Andrés Hamdan, Claudia Andrea Jurado, Andrés Felipe

Fuentes, Katherine Gómez, Luis Alfonso Gómez, Carlos Andrés Jurado and Andry Dilena Melo

Department of Surgical Sciences, University of Cauca, Colombia

Submission: April 02, 2018; Published: April 10, 2018

*Corresponding author: Juan Manuel Concha, Faculty of Health, Department of Surgical Sciences, University of Cauca, Carrera 613 N-50 Popayán, Colombia, Tel: (+572) 8209800; 8209870; Email: juanconcha@unicauca.edu.co

\begin{abstract}
Hoffa fractures of the femoral condyle are uncommon coronally-oriented injuries which extends through either the medial or lateral condyle. Most commonly affecting the lateral condyle. The usual mechanism of injury is a combination of vertical shearing and twisting forces [1]. We report a displaced intrarticular distal femoral fracture (Hoffa Letenneur Type I fracture) that occurred in a in a 15-year-old patient, when he fell from a moving vehicle. Internal fixation using a lateral approach and femoral epicondylar osteotomy was performed. This approach affords direct observation and exposure of the posterior lateral femoral condyle and lateral tibial plateau for open management of intraarticular disorders [2]. The fracture could be anatomically reduced and fixed, the recovery was complete and there were no sequela after one year of follow-up.

Keywords : Distal femoral fracture; Hoffa fracture; Epicondylar osteotomy
\end{abstract}

Case Report
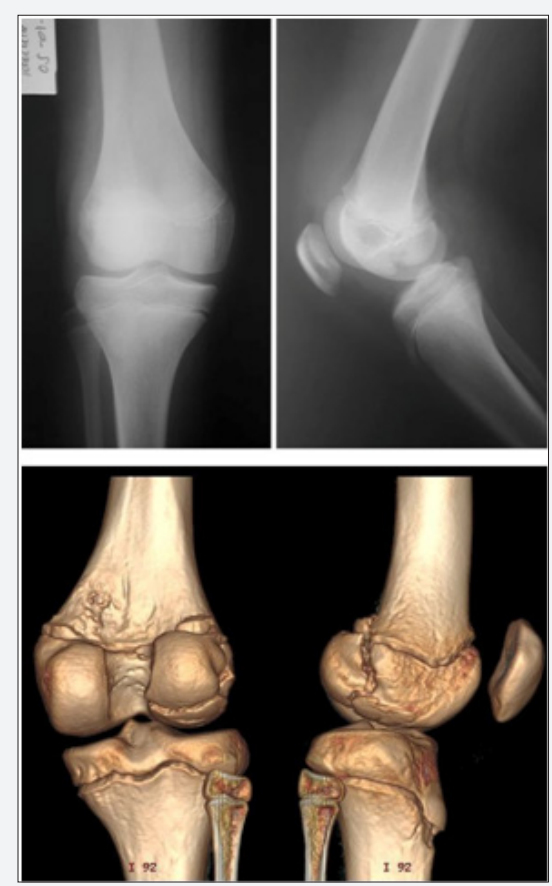

Figure 1: CT scan and plain radiograph show a Hoffa Letenneur Type I fracture.

A 15-year-old patient presented to the emergency department at Hospital Susana López de Valencia after he had fallen from a moving vehicle with an isolated closed injury to the right knee. A painful, swollen flexed knee was found and the patient was unable to perform any active movement. X Rays and tomography reveled a lateral Hoffa Letenneur Type I fracture [3] (Figure 1).

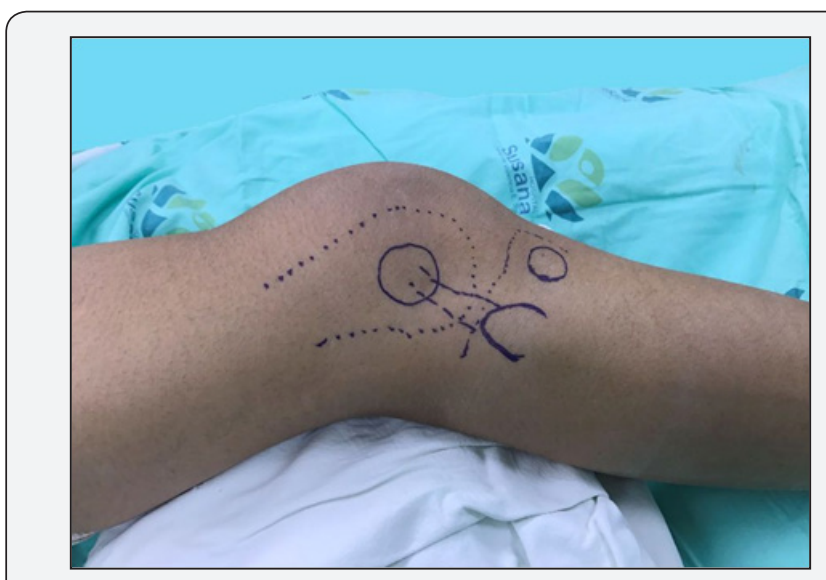

Figure 2: The bony landmarks of the lateral knee are marked.

Open reduction and internal fixation with $4,5 \mathrm{~mm}$ HCS counter sinkables crews (DePuy Synthes) was performed according with Bowers and Huffman description [2]. With the patient under spinal anesthesia in supine position with a bump under the ipsilateral hip, the leg was prepared and draped, the bony landmarks including the fibular head, the Gerdy's tubercle, lateral femoral epicondyle and lateral collateral ligament were marked 


\section{Juniper Online Journal of Case Studies}

(Figure 2). A curvilinear incision was made at the midportion of the ilio-tibial band and sharp dissection was carried through the skin and subcutaneous tissues. Blunt dissection with a moist sponge was used to elevate and dissect full-thickness tissue flap santeriorly over the ITB and lateral femoral epicondyle and posteriorly over the biceps femoris tendon and myotendinous junction. The common peroneal nerve then was identified and a vessel loop placed around it (Figure 3).

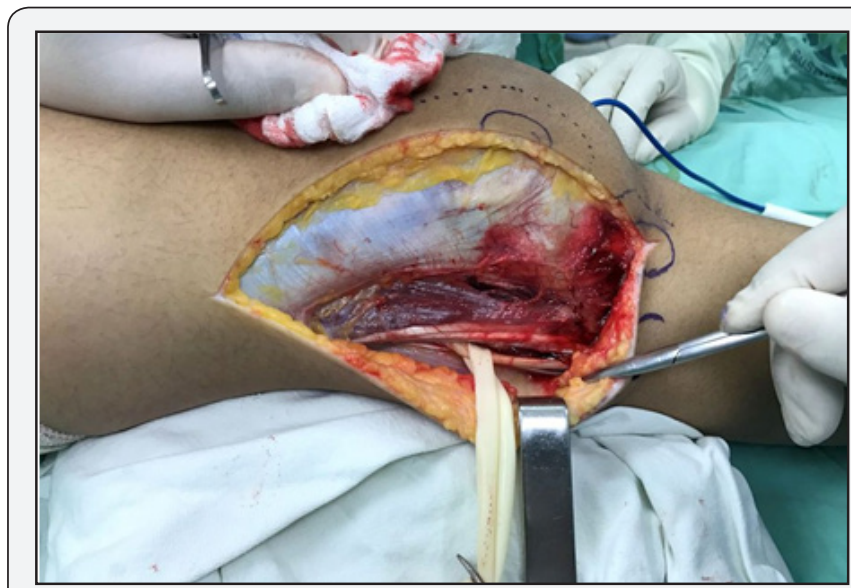

Figure 3: The common peroneal nerve (CPN) is identified and tagged behind the short head of the biceps femoris.

The ITB was splited longitudinally in line with its fibers directly over the lateral femoral epicondyle. The lateral collateral ligament, popliteofibular ligament, lateral capsule, and popliteus tendon then were exposed. The femoral origin of these structures was outlined with electrocautery and the center of the epicondyle was marked (Figure 4).

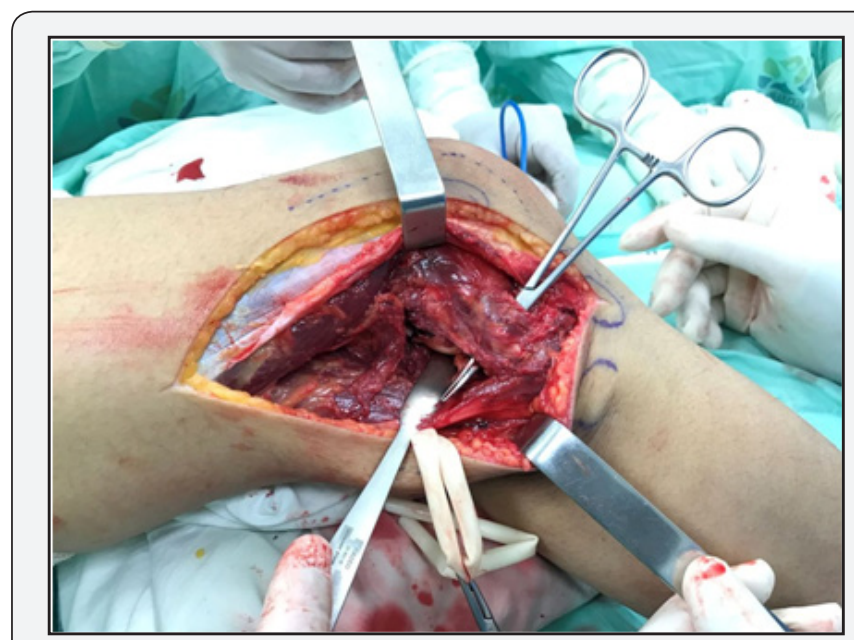

Figure 4 : The LCL is isolated.

A square window of the lateral femoral epicondyle then was osteotomized using a saw and a curved osteotome, The posterolateral complex, including the osteotomized lateral femoral epicondyle, then was retracted distally andheld with the weight of a towel clamp placed through the drill hole. The lateral hemijoint and the fracture then were exposed (Figure 5).

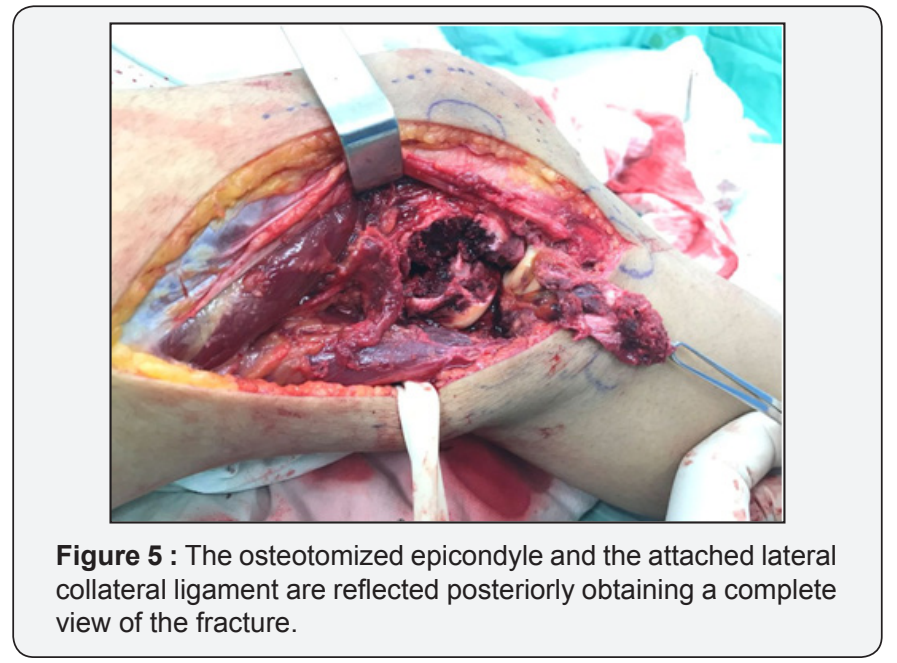

The fracture was reduced using a pointed reduction forceps and easily fixed under direct vision (Figure 6). A C-arm image intensifier was used to control reduction and screw placement (Figure 7). Finally the Gerdy's tubercle, was rigidly fixed with another HCS screw, however a partially threaded $4.0 \mathrm{~mm}$ cancellous screw and washer can also be used. The iliotibial band was closed primarily with absorbable braided suture. Immediate use of full continuous passive motion was started followed by a physiotherapy plan. Full wight bearing was allowed after 6 weeks of the surgery.

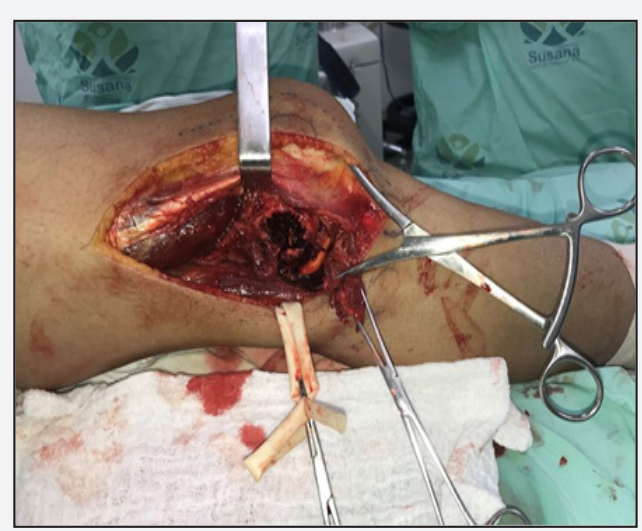

Figure 6 : Fracture reduction using pointed reduction forceps.

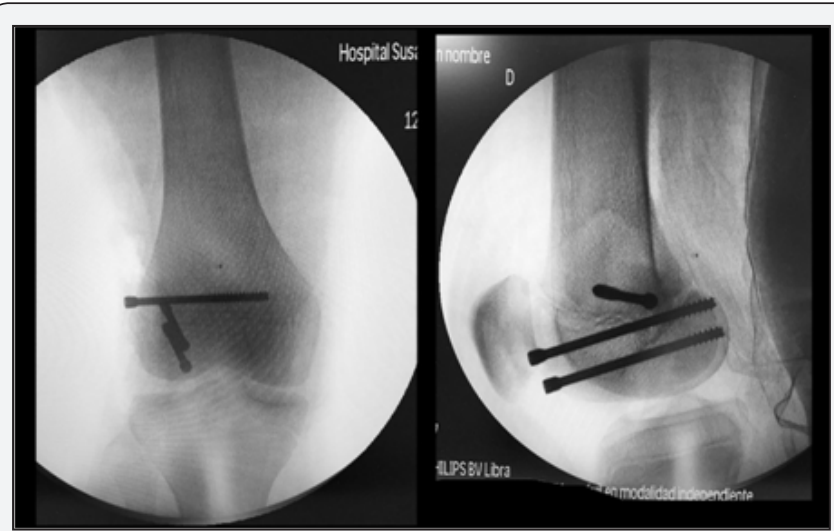

Figure 7 : C Arm - Image. 
At 12 weeks post operatively both the fracture and the osteotomy had healed (Figure 8) and the patient had complete range of motion and a stable knee (Figure 9).

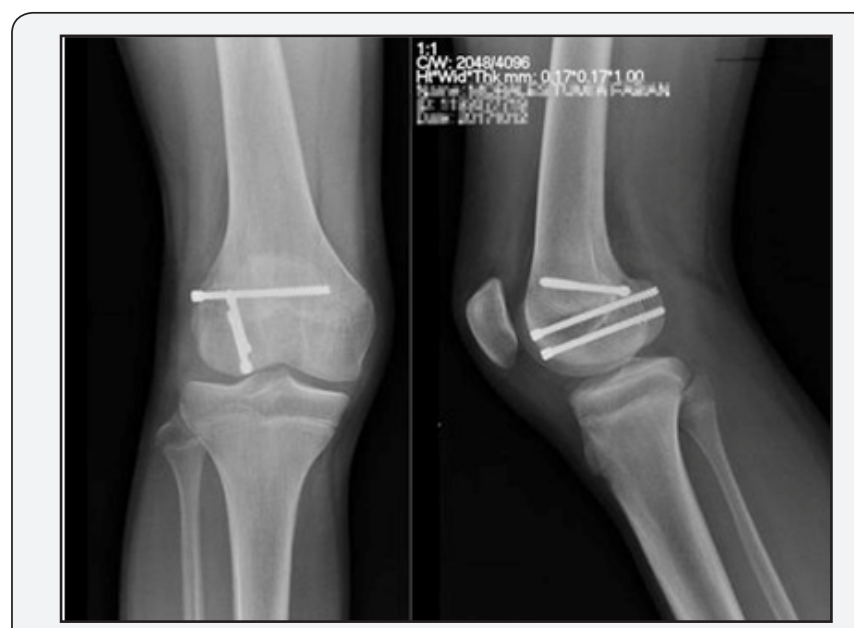

Figure 8 : Fracture healed after 12 weeks.

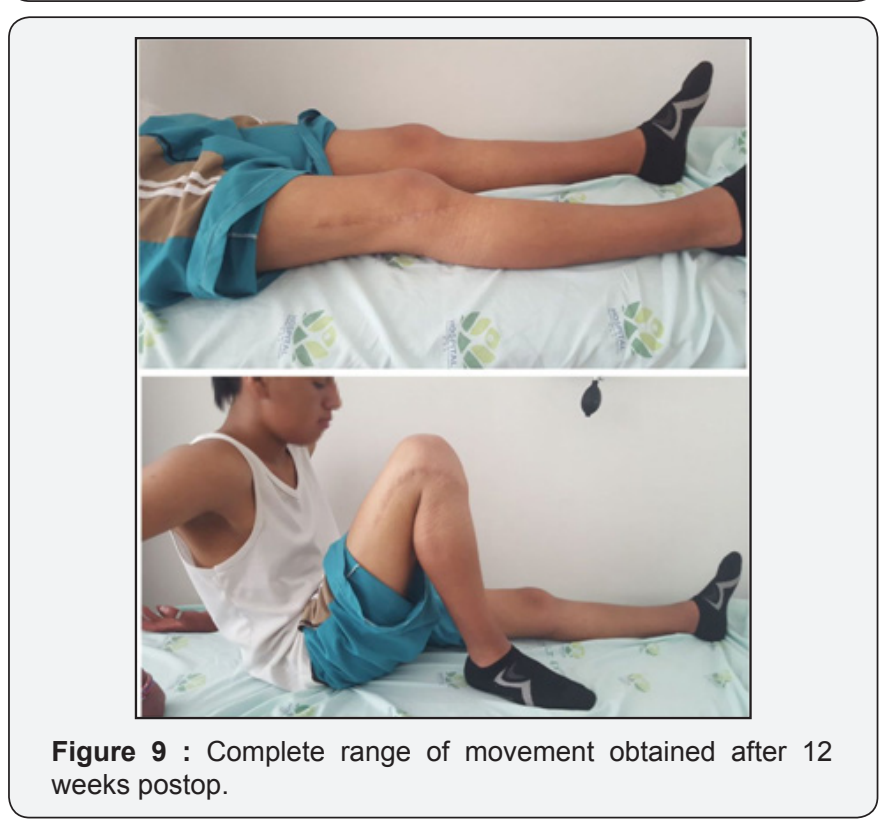

Discussion

The unicondylar tangential posterior fracture of the femur (Hoffa fracture) is an unusual injury, most commonly affecting the lateral condyle [4]. The mechanism of injury is not agreed upon, but it seems to imply an oblique transverse force resulting from the impaction of the upper part of the tibia on the femoral condyles, particularly the lateral condyle, withthe knee flexed greater than $90^{\circ}$. Hoffa fractures are very rare in adolescents and children, McDonough [5] reported a Hoffa fracture in a eightyear-old child that subsequently went on to nonunion.

Letenneur [3] in 1978, classified these fracture into 3 types depending on the distance of the fracture line from the posterior femoral cortex and it's direction, Type I fractures extend from an extra-articular location at the junction of the posterior femoral shaft and the proximal aspect of the femoral condyle to the posterior aspect of the condylar articular surface. The popliteus tendon insertion and the lateral head of the gastrocnemius origin remain attached to the condylar fragment. The anterior cruciate ligament (ACL) and lateral ligament insertions may be attached to either the condylar fragment or femoral shaft. Type II originate posterior to the posterior femoral shaft-condylar junction and are therefore potentially entirely intra-articular. Compared to type I fractures, the insertions are less likely to be attached to the condylar fragment. The type II fracture includes three subtypes based on their size: type a has the largest fracture fragment (resulting in a fracture fragment approximately $75 \%$ of the size of the type I fracture); type $b$ as a smaller fracture fragment (approximately 50\% of the size of the type I fracture); type $\mathrm{c}$ has the smallest fracture fragment (approximately 25\% of the size of the type I fracture). Type III is a fracture oblique to the femur. In type III fractures, the ACL and lateral ligamentous insertions remain attached to the condylar fragment [3].

The diagnosis may be missed because the fracture is obscured in the anteroposterior projection by the intact anterior part of the condyle. In lateral view, the fracture can hardly be seen if it is minimally displaced, our case is a clear example [6]. Preoperative computed tomographic (CT) evaluation is necessary for the confirmation of the diagnosis.

It is generally accepted that surgical stabilization is necessary to achieve satisfactory function following a Hoffa fracture [4], and depending on the location of the fracture, diferent approaching options have been proposed, Holmes et al. [7], reported a series of five Hoffa fractures (including one nonunion) employing a protocol of open reduction and internal fixation with lag screws through a formal parapatellar approach with good results. Patel et al. [8] reported a series of seven adult patients with Hoffa fractures treated using an anterior midline approach with good results without significant complications.

Open exposure of the posterolateral corner of the knee is challenged by limitations of posterolateral ligamentous tissues and posterior neurovascular structures, lateral femoral epicondylar osteotomy allows to gain extensile exposure to the posterolateral articular structures of the knee, and makes easy the direct reduction and fixation of lateral coronal distal femoral fractures.

This exposure greatly enhances posterolateral exposure compared with other described approaches, including a split in the iliotibial band or isolated osteotomy of the iliotibial band from Gerdy's tubercle [2].

The lateral femoral epicondylar osteotomy provides excellent visualization of the coronal fracture for achieving anatomical reduction and rigid internal fixation and we consider this technique a safe, reproducible and adequate technique.

\section{References}

1. Papadopoulos AX, Panagopoulos A, Karageorgos A, Tyllianakis M (2004) operative treatment of unilateral bicondylar hoffa fractures. J Orthop Trauma 18(2): 119-122. 
2. Bowers AL, Huffman GR (2008) Lateral femoral epicondylar osteotomy: an extensile posterolateral knee approach. Clin Orthop Relat Res 466(7): 1671-1677.

3. Letenneur J, Labour PE, Rogez JM, Lignon J, Bainvel JV (1978) Hoffa's fractures. Report of 20 cases (author's transl). Ann Chir 32(3-4): 213219.

4. Lewis SL, Pozo JL, Muirhead-Allwood WFG (1989) Coronal fractures of the lateral femoral condyle. J Bone Joint Surg Br 71(1): 118-120.

5. McDonough PW, Bernstein RM (2000) Nonunion of a Hoffa fracture in a child. J Orthop Trauma 14(7): 519-521.
6. Holmes SM, Bomback D, Baumgaertner MR (2004) Coronal fractures of the femoral condyle: a brief report of five cases. J Orthop Trauma 18(5): 316-319.

7. Ostermann PA, Neumann K, Ekkernkamp A, Muhr G (1994) Long termresults of unicondylar fractures of the femur. J Orthop Trauma 8(2): 142-146.

8. Patel NB, Lil NA, Bhavsar NM (2014) Coronal plane "Hoffa" fractures of the distal femoral condyle treated using an anterior approach. Gujarat Medical Journal 69(2).

\section{Your next submission with Juniper Publishers will reach you the below assets}

- Quality Editorial service

- Swift Peer Review

- Reprints availability

- E-prints Service

- Manuscript Podcast for convenient understanding

- Global attainment for your research

- Manuscript accessibility in different formats

( Pdf, E-pub, Full Text, Audio)

- Unceasing customer service

Track the below URL for one-step submission https://juniperpublishers.com/online-submission.php 